\title{
Headache in kidney transplantation
}

\author{
Ferdinando Maggioni - Maria Cristina Mantovan · Paolo Rigotti - Roberto Cadrobbi • \\ Federico Mainardi · Edoardo Mampreso - Mario Ermani - Silvia Cortelazzo • \\ Giorgio Zanchin
}

Received: 28 May 2009/ Accepted: 30 July 2009/Published online: 27 August 2009

(C) Springer-Verlag 2009

\begin{abstract}
The aim of this retrospective study was to determine the relevance of the symptom "headache" in kidney transplanted patients, since few studies have considered headache as a clinically significant complication in this condition. A total of 83 consecutive kidney transplant patients underwent to neurological examination and a detailed headache history was taken. The headache history considered the period before kidney disease, during renal failure, during dialysis treatment and after transplantation. Diagnosis was made according to International Headache Criteria (ICDH-II) (2004). Our results reveal an occurrence of headache after kidney transplantation in $44.5 \%$ of the patients, which is higher than rates reported for the general population and in the only specific comparable study on liver transplant patients. These data suggest the need for prospective studies to explore the causal mechanisms by which headache develops with frequency in kidney transplant patients, and in particular to determine the role of immunosuppressive therapy.
\end{abstract}

F. Maggioni ( $\square)$ - E. Mampreso · M. Ermani · S. Cortelazzo ·

G. Zanchin

Headache Centre, Department of Neurosciences,

University of Padua, Via Giustiniani, 5, 35128 Padua, Italy

e-mail: ferdinando.maggioni@unipd.it

M. C. Mantovan

Department of Neurology, Hospital of Mestre,

Venice, Italy

P. Rigotti · R. Cadrobbi

Department of General Surgery, University of Padua,

Padua, Italy

F. Mainardi

Headache Centre, Department of Neurology,

Hospital SS. Giovanni e Paolo, Venice, Italy
Keywords Headache - Migraine ·

Kidney transplantation - Cyclosporine

\section{Introduction}

One of the most outstanding contributions to modern medicine has been the introduction of therapeutic organ transplantation. Despite their spectacular and resolutive nature, these procedures are not free of complications in transplant recipients. Neurological problems in particular, occur with a frequency of 20-60\%, depending on the organ transplanted [1]. The percentage is higher for heart and bone marrow transplants, and lower in kidney recipients [1]. Neurological complications can be subdivided into those common to all transplants and those specific for a given type of transplant. Headache, in particular, is a nonspecific complication with a prevalence that varies between 3.2 and $35.2 \%$ according to the studies [2,3]. Whereas major complications occurring after transplantation have been investigated [4-6], headaches are infrequently discussed as a clinically significant problem in the transplant literature, since they are generally considered less important than other complications such as encephalopathy, infectious diseases of the central nervous system, blood hypertension, organ rejection, therapy with cyclosporine or FK 506 [1, 7-10]. However, headaches have an important negative effect on life satisfaction of these patients according to Matas et al. [11]. To the best of our knowledge, only one study specifically dealt with headaches, and in particular migraine [3]. Other publications involve only case reports [12-17]. Table 1 summarises data published on the incidence of neurological complications and, when reported, of headache and migraine for different transplant types [18-29]. Results are quite variable, but it is difficult 
Table 1 Occurrence of neurological complications in heart, kidney, liver, lung and heart-lung transplants in some studies

\begin{tabular}{|c|c|c|c|c|c|c|c|c|}
\hline \multirow[t]{2}{*}{ Author (reference) } & \multirow{2}{*}{$\begin{array}{l}\text { Type of } \\
\text { transplant }\end{array}$} & \multirow[t]{2}{*}{ No. of patients } & \multicolumn{2}{|c|}{ Neurological complications } & \multicolumn{2}{|c|}{ Headache } & \multicolumn{2}{|c|}{ Migraine } \\
\hline & & & $\begin{array}{l}\text { No. } \\
\text { patients }\end{array}$ & $\%$ & $\begin{array}{l}\text { No. } \\
\text { patients }\end{array}$ & $\%$ & $\begin{array}{l}\text { No. } \\
\text { patients }\end{array}$ & $\%$ \\
\hline Hotson et al. 1976 [4] & Heart & 83 & 45 & 54 & $\mathrm{nr}$ & & $\mathrm{nr}$ & \\
\hline Andrew et al. 1990 [5] & Heart & 90 & 6 & 7 & $\mathrm{nr}$ & & $\mathrm{nr}$ & \\
\hline Adams et al. 1986 [18] & Kidney & 467 & 140 & 30 & 15 & 3 & ns & \\
\hline Kahan et al. 1989 [19] & Kidney & 402 & ns & & $\mathrm{nr}$ & & $\mathrm{nr}$ & \\
\hline Christe 1994 [9] & Liver and kidney & 576 & ns & & 180 & 31 & $\mathrm{nr}$ & \\
\hline William et al. 1985 [20] & Liver & 29 & ns & & 3 & 10 & $\mathrm{nr}$ & \\
\hline de Groen et al. 1987 [21] & Liver & 48 & 13 & 27 & $\mathrm{nr}$ & & $\mathrm{nr}$ & \\
\hline Stein et al. 1992 [22] & Liver & 40 & 13 & 33 & 3 & 7 & $\mathrm{nr}$ & \\
\hline Frank et al. 1993 [23] & Liver & 56 & ns & & 18 & 32 & $\mathrm{nr}$ & \\
\hline Moreno et al. 1993 [24] & Liver & 143 & 19 & 13 & $\mathrm{nr}$ & & ns & \\
\hline Burkhalter et al. 1994 [7] & Liver & 100 & 34 & 34 & $\mathrm{nr}$ & & $\mathrm{nr}$ & \\
\hline Steiger et al. 1994 [3] & Liver & 34 & $\mathrm{nr}$ & & 12 & 35 & 6 & 18 \\
\hline Guarino et al. 1996 [25] & Liver & 199 & 63 & 32 & $\mathrm{nr}$ & & $\mathrm{nr}$ & \\
\hline Goldstein et al. 1998 [26] & Lung, heart-lung & 100 & 32 & 32 & 14 & 15 & $\mathrm{nr}$ & \\
\hline Jarquin-Valdivia et al. 1999 [27] & Heart & 137 & 25 & 18 & $\mathrm{nr}$ & & $\mathrm{nr}$ & \\
\hline Cemillàn et al. 2002 [28] & Heart & 205 & 95 & 48 & 21 & 11 & $\mathrm{nr}$ & \\
\hline Kim et al. 2004 [29] & Kidney (cy) & 56 & $\mathrm{nr}$ & & ns & 2 & $\mathrm{nr}$ & \\
\hline Kim et al. 2004 [29] & Kidney (tc) & 41 & $\mathrm{nr}$ & & ns & 12 & $\mathrm{nr}$ & \\
\hline
\end{tabular}

When reported, data regarding headache and migraine are given

$n r$ not reported, $n s$ not specified, $c y$ cyclosporine, $t c$ tacrolimus

to compare them owing to the different methods used. In this study we considered the occurrence of different headache types in a group of renal transplanted patients before and during renal failure (RF), during dialysis, after transplantation.

\section{Methods}

A total of 83 consecutive patients (55 males, 28 females; mean age $41.7 \pm 11.8$, range $18-63$ ) at least 6 months after transplantation were included in the study. All the patients underwent orthotopic renal transplant at the General Surgery Department of our University. Data on patient age at the time of transplantation and the course of the illness are summarised in Tables 2 and 3. The most frequent diseases underlying RF were glomerulonephritis (53\% of patients) and polycystic kidney disease (13\%), followed by diabetes mellitus, ureteral malformation and systemic lupus erythematosus. A patient questionnaire was used to collect anamnestic information, with specific regard to pharmacological history and headache characteristics during distinct periods: before RF; during RF; during dialysis treatment; after the transplant. The headaches were classified according to ICHD-II criteria [30]. All the patients underwent a general and neurological
Table 2 Age at transplantation $(n=83)$

\begin{tabular}{lcc}
\hline Age & Male & Female \\
\hline$<20$ & 0 & 1 \\
$20-30$ & 8 & 7 \\
$31-40$ & 15 & 4 \\
$41-50$ & 15 & 11 \\
$>50$ & 17 & 5 \\
Total & 55 & 28 \\
\hline
\end{tabular}

Table 3 Time elapsed in the different conditions $(n=83)$

\begin{tabular}{lccc}
\hline Time & Renal failure & Dialysis & Transplantation \\
\hline 1-6 months & 2 & 0 & 0 \\
6-12 months & 17 & 18 & 43 \\
1-3 years & 18 & 35 & 27 \\
3-6 years & 20 & 20 & 7 \\
6 years & 26 & 10 & 6 \\
\hline
\end{tabular}

examination. Blood pressure, weight, blood biochemistry parameters and cyclosporine dosage were measured and records of the same parameters from previous visits were obtained. All the patients were on immunosuppressive therapy with cyclosporine and corticosteroid; in addition, 
a large group was being treated with anti-hypertensive therapy.

Considering that all analysed variables were qualitative, a non parametric analysis was performed with the Pearson's $\chi^{2}$ and the McNemar's $\chi^{2}$ tests. The significant level was set at $P<0.05$.

\section{Results}

The pattern of headache in the 83 patients during the various periods of their history is shown in Table 4. In group A (before RF), 27 patients suffered from headache: 17 migraines without aura (MO), eight episodic tension-type headache (ETTH) and two hypertension-related (HR). In group B (during RF), the 36 patients suffering from headache comprised $20 \mathrm{MO}$, two ETTH, $13 \mathrm{HR}$, one metabolic headache $(\mathrm{MH})$. Of those with MO, 12 patients had suffered before RF and eight were new cases. For the other five MO patients in group A, MO ceased in four and one developed HR. The two ETTH cases had also suffered before RF; of the six remaining ETTH patients in group A, three developed HR, whereas in three headache ceased. Out of HR group, 11 were new cases and two patients had already suffered before RF. In group C (during dialysis) (Table $4 \mathrm{c}$ ), the 33 headache sufferers comprised seven MO, one ETTH, three HR, 22 dialysis headache (DH). All the group $\mathrm{C}$ MO patients had been in the same category in group $\mathrm{B}$; of the remaining 13 group $\mathrm{B}$ MO patients, $\mathrm{MO}$

Table 4 Occurrence of headache during the different periods of the history of the patients $(n=83)$

\begin{tabular}{|c|c|c|c|c|c|c|c|c|}
\hline \multirow[t]{2}{*}{ Type of headache } & \multicolumn{2}{|l|}{ A } & \multicolumn{2}{|l|}{ B } & \multicolumn{2}{|l|}{$\mathrm{C}$} & \multicolumn{2}{|l|}{ D } \\
\hline & $N$ & $\%$ & $N$ & $\%$ & $N$ & $\%$ & $N$ & $\%$ \\
\hline MO & 17 & 20.5 & 20 & 24.0 & 7 & 8.4 & 15 & 18.0 \\
\hline ETTH & 8 & 9.6 & 2 & 2.4 & 1 & 1.2 & 10 & 12.0 \\
\hline MO + ЕTTH & 0 & 0 & 0 & 0 & 0 & 0 & 2 & 2.4 \\
\hline DH & 0 & 0 & 0 & 0 & 22 & 26.5 & 0 & 0 \\
\hline $\mathrm{NC}$ & 0 & 0 & 0 & 0 & 0 & 0 & 4 & 4.8 \\
\hline HR & 2 & 2.4 & 13 & 15.7 & 3 & 3.6 & 2 & 2.4 \\
\hline MH & 0 & 0 & 1 & 1.2 & 0 & 0 & 0 & 0 \\
\hline PSH & 0 & 0 & 0 & 0 & 0 & 0 & 1 & 1.2 \\
\hline CY & 0 & 0 & 0 & 0 & 0 & 0 & 2 & 2.4 \\
\hline OKT3 & 0 & 0 & 0 & 0 & & & 1 & 1.2 \\
\hline Total & 27 & 32.5 & 36 & 43.3 & 33 & 39.7 & 37 & 44.5 \\
\hline
\end{tabular}

$N$ number of patients, $A$ before renal failure, $B$ during renal failure, $C$ during dialysis, $D$ after transplant, $M O$ migraine without aura, ETTH episodic tension-type headache, $D H$ dialysis headache, $N C$ not classifiable headache, $H R$ hypertension related, $M H$ metabolic headache, $P S H$ primary stabbing headache, $C Y$ cyclosporine related headache, OKT3 OKT3 related headache ceased in eight and five developed DH. The group C ETTH patient had been in the same category in group B. Of the 22 DH patients 13 were new cases and nine had been categorised in group B (five MO, three HR and one ETTH). In group D (after transplantation), 37 patients suffered of headache: $15 \mathrm{MO}, 10 \mathrm{ETTH}$, two ETTH + MO, two HR, four not classifiable (NC), two cyclosporine related (CY), one OKT3 related headache (OKT3), one primary stabbing headache (PSH). Twenty three of whom were new cases (six MO, seven ETTH, two ETTH + MO, four NC, two $\mathrm{CY}$, one OKT3, one PSH). Conversely, 26 patients suffering from headache $(10 \mathrm{MO})$ before transplant were free of attacks at 6-12 months follow up.

In order to evaluate a possible significance of the different headache occurrence before and after transplant, we subdivided the headache patients into two groups, considering in the first only migraine patients and in the second all the other kind of headaches. In the first group, 17 (20\%) patients suffered of MO before the transplant, $15(18 \%)$ MO post transplant, without statistical significance (McNemar's $\left.\chi^{2} P=0.79\right)$. In the second group, 10 (12\%) patients presented headache before transplant, $22(26.5 \%)$ after, with statistical significance (McNemar's $\chi^{2}$ $P=0.004)$.

All patients received immunosuppressive therapy of both cyclosporine and prednisone at dosages depending on the time elapsed since transplantation and clinical condition. To investigate a possible correlation between the headache and levels of cyclosporine and/or creatinine, we examined the post transplant follow-up results at 7 days and 1-3-6-12 months for patients who had cyclosporine and creatinine levels above the normal range. There were no significant differences for both between patients with and without headache (Pearson's $\chi^{2} P=0.43$ for cyclosporine and $P=0.73$ for creatinine). We were able to establish a definite relationship with cyclosporine administration only in two cases in which the lowering the high cyclosporine level within the normal range, was followed by headache disappearance.

Furthermore, 64 patients received azotioprine, 73 antihypertensive therapy; among the latter, 25 were treated with the beta-blockers, 18 with metoprolol, seven with atenolol. Table 5 summarises the data on the occurrence of MO in transplant patients with and without beta-blocker treatment. Comparison of the data reveals that administration of these anti-hypertensive agents, which are known to protect against migraine, did not influence MO development. Indeed, the onset or disappearance of MO showed no relation with doses nor with the type of beta-blocker used (metoprolol 50-200 mg, atenolol 50-100 mg). Tables 6 and 7 list the patient characteristics and the pattern of migraine attacks for subjects who developed $\mathrm{MO}$ after transplantation. 
Table 5 MO patients treated and not treated with betablockers in the different conditions

\begin{tabular}{llll}
\hline MO & \multicolumn{2}{l}{ Timing in the assumption of beta blockers } \\
\cline { 2 - 4 } & $\begin{array}{l}\text { Before and } \\
\text { after transplant }\end{array}$ & $\begin{array}{l}\text { Introduced } \\
\text { after transplant }\end{array}$ & $\begin{array}{l}\text { Never } \\
\text { treated }\end{array}$ \\
\hline Before and after transplant & 1 & 3 & 4 \\
After transplant & 1 & 3 & 4 \\
Disappeared after transplant & 0 & 4 & 6 \\
\hline
\end{tabular}

Table 6 Patients who developed MO after transplant

\begin{tabular}{llllllllll}
\hline $\mathrm{N}^{\circ}$ & Age & Sex & RF etiology & RF length & Dialysis & $\begin{array}{l}\text { Time elapsed } \\
\text { after transplant }\end{array}$ & Symptoms & NE & Therapy \\
\hline 1 & 48 & F & pd & 8 & 2 & 2 & T, A & N & c, fur \\
2 & 38 & F & nk & 13 & 1 & $18 \mathrm{~m}$ & T, A, MF & N & c, dox, fur, metop, clon \\
3 & 20 & F & gn & $3 \mathrm{~m}$ & 2 & 3 & T & N & c, fur \\
4 & 33 & M & gn & $1 \mathrm{~m}$ & 1 & 7 & - & $\mathrm{N}$ & all, c, ena, nifed, metop \\
5 & 27 & F & gn & 9 & 3 & 1 & T & N & at, c \\
6 & 47 & M & gn & 2 & 1 & 3 & T & c, clon, fur, simv \\
7 & 30 & F & rm & 5 & 3 years 6 months & 2 & - & c \\
8 & 22 & M & pd & 2 & 6 months & 7 & all, c, clonidine, fur, metopr
\end{tabular}

$g n$ glomerulonephritis, $r$ renal failure, $m$ months, $r m$ renal malformation, $n k$ not known, $p n$ pyelonephritis, $p d$ polycystic kidney disease, $A$ asthenia, $N$ normal, $T$ tremor, $M F$ mnesic failure, $N E$ neurologic examination, all allopurinol, at atenolol, $c$ cyclosporine, clon clonidine, dox doxazosin, ena enalapril, fur furosemide, metop metoprolol, nifed nifedipine, simv simvastatin; times in years when non specified

Table 7 Attack features, treatments and associated headache in the patients with MO developed after transplant

\begin{tabular}{|c|c|c|c|c|c|c|}
\hline $\mathrm{N}^{\circ}$ & F H & 1st attack PT & Frequency of the attacks & Intensity & Treatment & Other headache \\
\hline 1 & A & 2 days & Every 3 months & Severe & NSADs & - \\
\hline 2 & A & 3 months & Every 15 days & Moderate-severe & NSADs & ETTH \\
\hline 3 & $\mathrm{P}$ & 5 months & $2-3$ at months & Severe & NSADs & - \\
\hline 4 & A & 2 months & Every $5-6$ months & Moderate-severe & Rest & ETTH \\
\hline 5 & $\mathrm{P}$ & 1 months & Monthly & Severe & Rest & - \\
\hline 6 & $\mathrm{P}$ & 6-7 months & Monthly & Severe & NSADs & - \\
\hline 7 & $\mathrm{P}$ & 3-4 months & Weekly & Mild-moderate & Rest & - \\
\hline 8 & A & 1 year & Weekly & Severe & NSADs & - \\
\hline
\end{tabular}

FH Family history for migraine, $A$ absent, $P$ present, $P T$ post transplant, $N S A D s$ not-steroidal anti-inflammatory drugs, ETTH episodic tensiontype headache

Finally, the group of patients suffering from MO that persisted after transplantation $(n=10)$ showed no relevant change in the pattern of attacks in either frequency or intensity.

\section{Discussion}

The results show that headache is a diffuse problem in the transplant patients, affecting $44.5 \%$ of the study subjects and requiring specific treatment or diagnostic procedure in $8 \%$. Comparing with the literature, the percentage of patients with headache is higher, respect to both liver and kidney transplant patients $31 \%$ and to liver transplant patients $7-35 \%[3,23]$. We found no reports on the prevalence of migraine after isolated kidney transplantation. In the only paper available on kidney transplant, headache affects only $3 \%$ of patients but this result is not comparable with ours, since this study considers only the acute complications occurring in the first 3 days after the surgical procedure [2]. Steigler et al. 1994 [3] reported migraine in $18 \%$ of liver transplanted patients, in agreement with the results found here.

According with IHS diagnostic criteria of headache induced by substance use or exposure (30), cyclosporine seems not to be a relevant factor in the development of 
headache and specifically of migraine; in the only two cases with a definite relationship, the headache was described as continuous, tightening, bilateral in location, and without neurovegetative symptoms, which disappeared on a decrease in cyclosporine dosage. However, we cannot exclude a role of cyclosporine in the genesis of headache not directly related to its high level; since in particular some patients may be predisposed to develop headache. About this point, if we consider that after transplant four patients presented no classifiable headache, condition not present before RF, during RF or during DH periods and situation de novo in four patients, seem possible that this therapy could somehow favour the development of headache, perhaps related to its vasoactive properties [31]; however, the exact mechanisms by which the immunosuppressive drugs could induce or exacerbate headache are unknown. Six of the eight cases who developed MO after transplantation had a low frequency of attacks, which does not seem to be related to the use of a drug taken continuously. In none of these cases, the symptomatology was considered so important as to require modification of cyclosporine use. In two cases, the age on presentation of migraine was relatively advanced (46 and 47 years) and the first attack occurred within 1 month after transplant, casting doubt on a causative mechanism different from simply casualness.

None of the patients reported migraine with aura (MA), a finding that differs from that of Steiger et al. [31], who reported that 5/34 liver transplant patients developed MA after surgery; among different hypothesis, this could possibly be related to the different transplant organ.

During dialysis, the number of patients with headache attributable to this procedure, without correlation with preexisting headache or migraine, was remarkable. On the other hand, we observed a decrease in the number of MO patients during dialysis. Furthermore, no new MO cases occurred during this period, which was long enough (dialysis duration at least 1 year in $70 \%$ of patients and at least 6 months in $>98 \%$ ) to exclude bias due to too short an observation period. We can hypothesise possible mechanisms related to the procedure of dialysis or to biochemical plasma changes in calcitonin gene-related peptide and substance $\mathrm{P}$ as recently demonstrated [32].

An important point is the antihypertensive therapy taken by patients, in particular beta-blockers, which represent an important prophylactic treatment. There are no differences for beta-blocker treatment in the distribution of patients who developed MO after transplantation, those with preexisting MO, or those for whom MO disappeared after transplant. In the three groups of patients with $\mathrm{MO}$, the distribution of the cases with MO developed after transplant, with pre-existing MO or indeed in which disappeared is the same. The new cases with MO in therapy with beta-blockers are four, in three the introduction of the drug was after transplant in one was pre-existing the transplant. Of the 10 patients in whom MO disappeared, beta-blocker treatment was started after transplantation in four and the remaining six patients were not treated. In conclusion, the treatment with beta-blockers may be a cause that produces some difficulties in the interpretation of the data, but the detailed analysis of the results seems to indicate that the distribution of the patients regarding the appearance or disappearance of MO in the various groups of patients is random.

After kidney transplant, we did not find an increase of MO cases, but a significant increase in the number of non specific headache such as "non classifiable" or ETTH.

Further studies on the occurrence of neurological complications in transplanted patients should take in account also the development of headache specifically of migraine. Besides clarifying the extent of this problem, such investigations could give clues on its causative mechanisms, particularly with regard to immunosuppressive therapy.

\section{Conflict of interest None.}

\section{References}

1. Patchell RA (1994) Neurological complications of organ transplantation. Ann Neurol 36:688-703

2. Adams DH, Ponsford S, Gunson B, Boon A, Honisberger L, Williams A, Buckels J, Elias E (1987) Neurological complications following liver transplantation. Lancet 1:949-951

3. Steiger MJ, Farrah T, Rolles K, Harvey P, Burroughs AK (1994) Cyclosporine and headache. J Neurol Neurosurg Psychiatry 57:1258-1259

4. Hotson JR, Pedley T (1976) The neurological complications of cardiac transplantation. Brain 99:673-694

5. Andrew BT, Hershon JJ, Calanchini P, Avery J, Hill D (1990) Neurologic complication of cardiac transplantation. West J Med 153:146-148

6. Sila CA (1989) Spectrum of neurologic events following cardiac transplantation. Stroke 20:1586-1589

7. Burkhalter E, Starzl T, Van Thiel DH (1994) Severe neurological complications following orthotopic liver transplantation in patients receiving FK 506 and prednisone. J Hepatol 21:572-577

8. Kahan BD (1989) Cyclosporine. N Eng J Med 321:1725-1738

9. Christe W (1994) Neurological disorders in liver and kidney transplant recipients. Transplant Proc 26:3175-3176

10. Wijdick EFM (1999) Neurologic complications in transplant recipients: a bird's-eye view. In: Wijdick EFM (ed) Neurologic complications in transplant recipients. Butterwoth Heineman, Boston, p 57

11. Matas AJ, Halbert RJ, Barr ML, Helderman JH, Hricik DE, Pirsch JD, Schenkel FA, Siegal BR, Liu H, Ferguson RM (2002) Life satisfaction and adverse effects in renal transplant recipients: a longitudinal analysis. Clin Transplant 16:113-121

12. Gharpune VS, Hutchinson RM, Durrant ST (1990) Migraine after bone-marrow transplantation. Lancet 335:57

13. Arns W (1994) Kopfschmerzen unter Ciclosporin-Therapie. DMW 119:1135 
14. Rozen TD, Wijdicks EFM, Hay JE (1996) Treatment refractory cyclosporine-associated headache: relief with conversion to FK506. Neurology 47:1347

15. Maggioni F, Mantovan MC, Moscardo P, Zanchin G (1997) Migraine after heart transplantation: case report and review of the literature. Nuova Riv Neurol 7:185-190

16. Maghrabi K, Bohlega S (1998) Cyclosporine-induced migraine with severe vomiting causing loss of renal graft. Clin Neurol Neurosurg 100:224-226

17. Toth C, Burak K, Becker W (2005) Recurrence of migraine with aura due to tacrolimus therapy in a liver transplant recipient successfully treated with sirolimus substitution. Headache 45:245-254

18. Adams HP, Dawson G, Coffman TJ, Corry RJ (1986) Stroke in renal transplant recipients. Arch Neurol 43:113-115

19. Kahan BD, Flechner SM, Lorber MI, Golden D, Conley S, Van Buren CT (1987) Complications of cyclosporine-prednysone immunosuppression in 402 renal allograft recipients exclusively followed at a single center for from one to five years. Transplantation 43:197-204

20. William R, Blackburn A, Neuberger J, Calne Y (1985) Long term use of cyclosporine in liver grafting. Q J Med 224:897-905

21. de Groen PC, Aksamit AJ, Rakela J, Forbes GS, Krom R (1987) Central nervous system toxicity after liver transplantation. N Engl J Med 317:861-866

22. Stein DP, Lederman RJ, Vogt DP (1992) Neurological complications following liver transplantation. Ann Neurol 31:644-649

23. Frank B, Perdrizet GA, White HM, Marsh JW, Leman W, Woodie ES (1993) Neurotoxicity of FK 506 in liver transplant recipient. Transplant Proc 25:1887-1888

24. Moreno E, Gomez SR, Gonzales I, Loinaz C, Garcia I, Perez A, Palomo C, Alvarado A, Maffettone F, Perez-Cerda F, Lumbreras C,
Colina F (1993) Neurologic complications in liver transplantation. Acta Neurol Scand 87:25-31

25. Guarino M, Stracciari A, Pazzaglia P, Sterzi R, Santilli I, Donato F, D’Alessandro R (1996) Neurological complications of liver transplantation. J Neurol 243:137-142

26. Goldstein L, Haug M, Perl J, Perl M, Maurer J, Arroliga A, Mehta A, Kirby T, Higgins B, Stillwell B (1998) Central nervous system complications after lung transplantation. J Heart Lung Transpl 17:185-191

27. Jarquin-Valdivia AA, Wijdicks EFM, McGregor C (1999) Neurologic complications following heart transplantation in the modern era: decreased incidence, but postoperative stroke remains prevalent. Transplant Proc 31:2161-2162

28. Cemillan CA, Alonso-Pulpon L, Burgos-Lazaro R, Millan-Hernandez I, del Ser T, Liano-Martinez H (2004) Neurological complications in a series of 205 orthotopic heart transplant patients. Rev Neurol 38:906-912

29. Kim BS, Lee SG, Hwang S, Park KM, Kim KH, Ahn CS, Moon DB, Ha TY, Song GW, Kim DS, Moon KM, Jung DH (2007) Neurologic complications in adult living donor liver transplant recipients. Clin Transplant 21:544-547

30. Headache Classification Subcommittee of the International Headache Society (2004) The international classification of headache disorders: 2nd edition. Cephalalgia 24(Suppl 1):9-160

31. Yardimci N, Colak T, Sevmis S, Benli S, Zileli T, Haberal M (2008) Neurological complications after renal transplant. Exp Clin Transplant 6:224-228

32. Alessandri M, Massanti L, Geppetti P, Bellucci G, Cipriani M, Fanciullacci M (2006) Plasma changes of calcitonin gene related peptide and substance $\mathrm{P}$ in patient with dialysis headache. Cephalalgia 26:1287-1293 